\title{
Relationship between employee performance, leadership styles and emotional intelligence in an organization
}

\author{
${ }^{1}$ Oladipo Kolapo Sakiru; ${ }^{2}$ Daskareem Vera Enoho; ${ }^{2}$ Salami Dada Kareem; \\ ${ }^{1}$ Mohammed Abdullahi. \\ ${ }^{1}$ Department of Human Resource Development, Universiti Putra Malaysia \\ ${ }^{2}$ Department of Economics, Faculty of Social Sciences, Lagos State University, Ojo. Lagos State, Nigeria
}

\begin{abstract}
The interest in great leaders keeps growing in modern occasions, as society and technology are becoming growing in more complexes. The ever altering organizational atmosphere needed leaders who are able to satisfy the challenges and demands of organizations functioning in competitive complex conditions, with world open for trade. This study looks into the relationship between worker performances, leadership styles and emotional intelligence within an organization. Information was collected, using three instruments, from the sample of 30leaders and150 raters. The Multifactor Leadership Questionnaire was utilized to look for the leadership style of the leaders in the organization. Worker performance was taken and recorded while using organization's performance evaluation process and the ECP factors are used to measure emotional intelligence. Leadership and emotional intelligence were recognized as the independent variables and worker performance as the dependent variable. Data acquired from each one of the research instruments ended up being statistically examined. Through linear regression analysis, and it has come to conclusion from the study that there's a substantial relationship between worker performance as well as an emotional intelligent, transactional leader. However, no significant linear relationship was discovered between worker performance as well as an emotional intelligent, transformational leader.
\end{abstract}

Keywords: Leadership, Employee's Performances, Emotional Intelligence. Organization

\section{Introduction}

As organizations as well as their conditions have changed rapidly in the last years, a brand new type of leadership, one that's less bureaucratic and much more democratic, is needed to be able to make sure the organization's survival and gratification (1). It's contended that leadership effectiveness has an optimistic effect on the organizational performance (2). Ultimately it's the numerous performances of people that culminate with the performance of the organization, or perhaps in the achievement of organizational goals. Leadership effectiveness is instrumental in making certain organizational performance (3). Consequently, many leadership ideas happen to be suggested within the last half a century hat are stated to possess affected the general effectiveness from the organizations where they've been employed. Within the competitive world organizational atmosphere, it is essential that organizations employ leadership styles which allow organizations to outlive inside a dynamic atmosphere (1).

Performance is definitely a progressively important concern for companies in Malaysia. Additionally, Malaysia organization isn't exempt out of this demand for performance. Performance continues to be based on (4) as the amount of a person's work achievement after getting exerted effort. (5) And (4) thought that performance is ultimately a person phenomenon with environment variables impacting on performance mainly through their impact on the person determinants of performance ability and motivation. (3) Confirmed the hyperlink between high end and leadership within the United States by creating a type of charming/transformational leadership in which the leaders' behavior is stated to produce inspiration, empowerment in the subordinates, leading to extremely high effort, extremely high commitment and readiness to consider risks. It's been broadly recognized that effective organizations require effective leadership, and business performance are affected indirect proportion towards the neglect of the employee (6).

In addition, it's generally recognized that the performance associated with a group is basically determined by the standard of their leadership. Effective leadership behavior facilitates the attainment from the subordinate's desires, which in turn leads to effective performance (6). A definition by (7) that includes nearly all different definitions all around the construct of leadership states that "leadership continues to be created in mind of group processes, ought to be personality, ought to be inducing compliance, because the exercise of influence, as particular actions, as a kind of persuasion, like an energy elation, being an instrument to attain goals, being an effect of interaction, like a classified role, being an initiation of structure, so that as many 
mixtures of this definition". Leadership continues to be changed with time, using the alternation in worker needs producing an interest in alternation in the connection from a leader and the subordinates.

It's been recommended that you will find two sights of leadership-the standard look at transactional leadership, including an exchange process between leader and subordinate, along with a look transformational leadership that enables for the development and transformation of individuals (10). An emotional awareness leader is able to supply subordinates having an obvious group of values which to use a Superior amount of emotional intelligence allow leaders to produce a mutually agreed group of values to facilitate the introduction of worker potential within the organization (11). Furthermore, leaders who exhibit a heightened degree of emotional intelligence will probably produce an appropriate context by which their subordinates are empowered to provide superior performance (11). Research by (12) signifies that transformation leadership is regarded as more emotion based than transactional leadership. These bits of information are in line with work by (13) and (12) and support (14) and (13) contention that effective leaders are socially adept. (4) Describes emotional intelligence as a range of cognitive abilities, abilities and expertise that influences an individual's ability to deal with environment demands and stress.

\section{Objectives of the Study:}

The broad objectives of the studies are to look at the relationship between worker performance, leadership styles and emotional intelligence in a Malaysia organization. In addressing the broad objective of the research, the following hypotheses were examined.

Ha1: There is a significant positive linear relationship between employee performance and an emotionally intelligent transactional leader.

Ha2: There is a significant positive linear relationship between employee performance and an intelligent transformational leader.

\section{Methodology of the Study:}

The goal from the present study ended up being to gain understanding around the relationship between worker performances, leadership and emotional intelligence within an organization. To reply to the question in the study, data happen to be collected from the managers and employees of the public sector organization at Selangor, Malaysia. The examples of 30 leaders interviewed within the sample and150 raters also interviewed within the sample. All subjects are fully informed regarding the character from the analysis. They all are assured that the information collected were completely private. The questionnaire is distributed towards the participants and given two days to fill the questions.

\section{Instruments}

Three instruments were utilized in these studies; the Multifactor leadership questionnaire was used to obtain the evaluation of leadership behavior and organizational effectiveness, (15), the ECP (16) and also the parastatal performance evaluation process.

\section{Results and Discussions}

Table 1:Cronbach's Alpha Reliability Coefficients for MLQ Factors

\begin{tabular}{|l|c|c|c|}
\hline Leadership Factors & Mean & $\begin{array}{c}\text { Standard } \\
\text { Deviation }\end{array}$ & $\begin{array}{c}\text { Cronbach's Alpha } \\
\text { Reliability } \\
\text { Coefficients }\end{array}$ \\
\hline Idealized Attributes & 3.8673 & .76828 & 0.747080 \\
Idealized Behaviours & 3.9801 & .57266 & 0.747080 \\
Inspirational Motivation & 3.8113 & .68189 & 0.762428 \\
Individualized Consideration & 3.8201 & .68604 & 0.718303 \\
Contingent Reward & 4.0254 & .68644 & 0.789243 \\
Management-by-exception(active) & 3.5464 & .73816 & 0.703047 \\
Management-by- exception(passive) & 3.8273 & .69855 & 0.698303 \\
Transformational Leadership & 3.6854 & .65285 & 0.920135 \\
Transactional Leadership & 3.8427 & .64940 & 0.889811 \\
\hline
\end{tabular}

The outcomes indicate that $M L Q$ factors are generally reliable. Therefore, with this research, the $M L Q$ instrument is really are reliable way of measuring transformational leadership and measuring transactional leadership. 
Table 2: Cronbach's alpha reliability coefficient scores for the ECP Factors

\begin{tabular}{|l|l|l|l|}
\hline $\begin{array}{l}\text { Emotional } \\
\text { Competency Factors }\end{array}$ & Mean & Standard Deviation & $\begin{array}{l}\text { Cronbach's Alpha } \\
\text { Reliability } \\
\text { coefficients }\end{array}$ \\
\hline Emotional Literacy & 3.6950 & 0.6950 & 0.923409 \\
\hline Self-Esteem & 3.6280 & 0.9630 & 0.873186 \\
\hline Self-Management & 3.1230 & 1.4590 & 0.871992 \\
\hline Self- Motivation & 3.2470 & 1.0070 & 0.880453 \\
\hline Change Resilience & 3.3520 & 0.7060 & 0.933527 \\
\hline Relationship Skills & 3.1040 & 0.9080 & 0.956451 \\
\hline $\begin{array}{l}\text { Integration of Head } \\
\text { and Heart }\end{array}$ & 3.0000 & 1.3440 & 0.911376 \\
\hline
\end{tabular}

The end result signifies the $E C P$ factors are reliable; it is therefore trustworthy way of measuring emotional intelligence.

\section{Result of hypotheses 1}

Ho1 There is no significant positive linear relationship between employee performance and an emotionally intelligent transactional leader.

Ha1 There is a significant positive linear relationship between employee performance and an emotionally intelligent transactional leader.

This hypothesis was tested by constructing the following linear model:

$\mathrm{PA}=$ Intercept $+\beta 1 *(\mathrm{EI})+\beta 2 *(\mathrm{TA})+\varepsilon$

Where: $P A=$ Employee Performance

$E I=$ Emotional Intelligence

$T A=$ Transactional Leadership

Summary of the Linear Regression model for Hypothesis 1

Table 3: Regression Summary for Dependent Variable; PA $R=0.18621913 R^{2}=0.03467756$ Adjusted $R^{2}=0.02799713$ F $(2,289)=5.1909, p<0.00610$

\begin{tabular}{|l|l|l|l|l|}
\hline & \multicolumn{1}{|c|}{$\mathbf{B}$} & Std.Err. & \multicolumn{1}{|c|}{$\mathbf{t ( 2 8 9 )}$} & p-level \\
\hline Intercept & 3.799793 & 0.135735 & 27.99425 & 0.000000 \\
\hline $\begin{array}{l}\text { Emotional } \\
\text { Intelligence }\end{array}$ & -0.000246 & 0.000520 & -0.47302 & 0.636553 \\
\hline $\begin{array}{l}\text { Transactional } \\
\text { Leadership }\end{array}$ & -0.010440 & 0.003892 & -2.68265 & 0.007725 \\
\hline
\end{tabular}

It's apparent this model has truly low correlation since the modified R2 is low (Modified R $\mathbf{R}^{2} .02799713$ ), and merely $3 \%$ in the variation in worker performance is referred to with this particular model. This model is significant $(\mathrm{F}(2,289)=5.1909, \mathrm{p}=.006)$. The researcher REJECTS the null hypothesis (Ho1) and concludes that there is sufficient evidence, at 5\% level of significance, that you have a linear relationship between worker performances with an emotional intelligence transactional leader. The running parameters will be the intercept $(\mathrm{t}=27.99425$, amounts of freedom $(\mathrm{df})=289, \mathrm{p}<0.001)$ and transactional leadership parameter $(\mathrm{t}=-2.68265, \mathrm{df}=$ $289, \mathrm{p}=0.0077)$. The emotional intelligence parameter is not significant $(\mathrm{t}=-0.47302, \mathrm{df}=289, \mathrm{p}=0.6366)$ in this model. This implies that emotional intelligence is not having a significant effect on the employee performance scores, when considered in this model. However, there is a negative linear relationship between emotional intelligence and employee performance. This indicates that the relationship depends only on transactional leadership i.e. there is no effect due to emotional intelligence. The regression equation/model states that the employee performance value is estimated by a constant minus a small fraction $(-0.010440)$ of the transactional score.

Result of hypothesis 2

Ho2 There is no significant relationship between employee performance and an emotionally intelligent transformational leader. 
Ha2 There is a significant relationship between employee performance and an emotionally intelligent transformational leader.

The hypothesis was tested by constructing the following linear model:

Table 4: Regression Summary for Dependent variable: $P A R=.13997618 R^{2}=.01959333$ Adjusted $\mathrm{R}^{2}=.01276123 \mathrm{~F}(2,287)=2.8678 \mathrm{p}<0.05845$

\begin{tabular}{|l|l|l|l|c|}
\hline & \multicolumn{1}{|c|}{$\mathrm{B}$} & Std. Err. & $\mathrm{t}(287)$ & $\mathrm{p}$-level \\
\hline Intercept & 3.752408 & 0.130289 & 28.80071 & 0.000000 \\
\hline Emotional Intellig & -0.000892 & -0.000655 & -1.36287 & 0.173992 \\
\hline $\begin{array}{l}\text { Transformational } \\
\text { leadership }\end{array}$ & -0.001308 & 0.002417 & -0.54096 & 0.588954 \\
\hline
\end{tabular}

It's apparent this model has truly low correlation (Modified $R^{2}=.01276123$ ). The model is simply mildly significant $(\mathrm{F}(2,287)=2.8678, \mathrm{p}=.05845)$. The investigator doesn't REJECT the null hypothesis $($ Ho2 $)$ and concludes that insufficient evidence, within the $5 \%$ quantity of significance, that you have a linear relationship between worker performances together with an emotional intelligent between transformational leaders. Really the only significant parameter might be the intercept $\left(\mathrm{t}=28.8, d f=80287, \mathrm{p}^{\sim}\right)$. The existence transformational leadership $(\mathrm{t}=-.54096, d f=287, \mathrm{p}=.588954)$ together with the emotional intelligence parameters $(\mathrm{t}=-1.36287$, $d f=287, \mathrm{p}=.173992$ ) aren't significant throughout this model

\section{Discussion}

The very first hypothesis looked into the connection between worker performance as well as an emotional intelligent, transactional leader. The outcomes from the linear regression analysis signifies that the significant linear relationship exists between worker performance as well as an emotional intelligent, transactional leader $(\mathrm{F}(2,289)=5.1909, \mathrm{p}=.006)$. The investigator thus rejects the null hypothesis $($ Hol $)$ and concludes that there's sufficient evidence, in the 5\% degree of significance, that there's a linear relationship between worker performance as well as an emotional intelligent transactional leader. It has to however be observed that the correlation is extremely low (Modified $R^{2}=.02799713$ ). In addition, the outcomes indicate that emotional intelligence doesn't have important effect on worker performance when considered within this model $(\mathrm{t}=-.47302, d f=289, \mathrm{p}=.6366)$. Although this model is important, the character from the relationship is really the dependent variable, worker performance, decreases because the independent variables of emotional intelligence and transactional leadership increase. Thus, the outcomes from the first hypothesis indicate the relationship in this particular model is negative. The $2^{\text {nd }}$ hypothesis looked into the connection between worker performance as well as an emotional intelligent, transformational leader. The outcomes of the linear regression analysis indicated that the significant linear relationship doesn't exist between worker performance as well as an emotional intelligent, transformational leader $(\mathrm{F}(2,287)=2.8678, \mathrm{p}=.05845)$. The investigator fails to reject the null hypothesis (Ho2) and concludes that there's inadequate evidence, in the $5 \%$ degree of significance, that there's a linear relationship between worker performance as well as an emotional intelligent transformational leader. The independent variables of emotional intelligence $(\mathrm{t}=-1.36287, d f=287, \mathrm{p}=.173992)$ and transformational leadership $(\mathrm{t}=-.54096, d f=287, \mathrm{p}=.588954)$ aren't significant. The outcomes indicate that emotional intelligence and transformational leadership doesn't have important effect on worker performance when talking about this model. In addition, the connection in the second hypothesis model can also be negative.

Based on relevant literature already examined, a substantial relationship was likely to exist between worker performance as well as an emotional intelligent, transformational leader, however this research doesn't confirmed the expectation. The findings of the research did not offer the conclusions attracted by authors for example (17), and (18), which claim that worker performance is going to be characterized by high amounts of transformational leadership minimizing amounts of transactional leadership. Furthermore, the outcomes of the foremost and second ideas don't concur using the literature and former research presented, as research by (15),(19),(20)and(21) indicate an optimistic relationship between leadership and worker performance and an optimistic relationship between leadership and emotional intelligence.

Both in linear regression analyses, ideas 1and 2, the negative regression coefficients led to an adverse relationship in the two models. These negative relationships in the models conflict with findings of (17),(19), (20) and(21). As a result, these negative regression coefficients contradict previous research and theory. This negative relationship in the models could however be credited towards the low variance from the parastatal performance evaluation scores, which managed to get hard to differentiate from a good along with a poor performance evaluation score. This might explain the problem in fitting significant theoretical models. These studies therefore doubt the theoretical models as incorrect and indicate that the outcomes of these studies was because of the possible lack of variability within the worker performance data. 


\section{Conclusion}

In line with the findings of the study, it had come to the conclusion that there's a statistically significant relationship between worker performance as well as an emotional intelligent, transactional leader. But there's no significant linear relationship between worker performance as well as an emotional intelligent, transformational leader. It had been noted that the linear regression research into the research created varying is a result of individuals anticipated, because the investigator expected a significant to exist between worker performance as well as an emotional intelligent, transformational leader. These bits of information contradict the values of prominent authors for example (17), (19), (20) and (21).

\section{References}

[1] MARITZ, D. 1995. "Leadership and mobilizing potential", Human Resource Management

[2] CHARLTON, G. 2000. Human Habits of Highly Effective Organizations'. Pretoria: Van Schaik Publishers.

[3] HELLRIEGEL, D., JACKSON, S.E. and SLOCUM, J.W. 1999. Management. Cincinnati: South-Western College Publishing.

[4] MAYER, J.D., SALOVEY, P. and CARUSO, D. 2000. "Emotional Intelligence meets traditional standards for intelligence", Intelligence, 27(4): 267-298.

[5] AMOS, T.L., RISTOW, A. and RISTOW, L. 2004. Human Resource Management ( $2^{\text {nd }}$ edition). Lansdowne: Juta and Co Ltd.

[6] BASS, B.M. 1990. Bass and Stogdill's handbook of leadership: Theory, Research and Managerial applications. New York: Free Press.

[7] BASS, B.M. 1997. "Concepts of Leadership". In Vecchio, R.P. (ed). Leadership:UnderstandingtheDynamics of Power and Influence in Organizations. Notre Dame:University of Notre Dame Press.

[8] CACIOPPE, R. 1997. "Leadership Moment by Moment”, Leadership and Organizational Development Journal, 18(7): 335-345.

[9] AVOLIO, B.J., WALDMAN, D.A. and YAMMARINO, F.J. 1991. "Leading in the 1990's:The Four I's of Transformational Leadership", Journal of European Industrial Training.

[10] BASS, B.M. 1994. "Transformational leadership", Human ResourceManagement, (2): 10-13.

[11] BASS, B.M. 1997. "Concepts of Leadership". In Vecchio, R.P. (ed). Leadership:UnderstandingtheDynamics of Power and Influence in Organizations. Notre Dame:University of Notre Dame Press.

[12] BASS, B.M. and AVOLIO, B.J. 2000. Multifactor Leadership Questionnaire. RedwoodCity:

[13] CACIOPPE, R. 1997. "Leadership Moment by Moment”, Leadership and Organizational Development Journal, 18(7): $335-345$.

[14] PALMER, B., WALLS, M., BURGESS, Z. and STOUGH, C. 2001. "Emotional intelligence and effective leadership", Leadership \& Organization Development Journal, 22(20): 1-7. PARASURAMAN, A. 1986. Marketing Research. Reading: Addison-Wesley Publishing Company.

[15] PERSONAL COMMUNICATION. 2004. Southern Region Human Resource Manager, TheParastatal, East London. April December.

[16] CAMPBELL, J., McClOY, R., OPPLER, S. and SAGER, C. 1993. The Theory of Performance. New York: Jossey-Bass

[17] PAULUS, P.B., SETA, C.E. and BARON, R.A. 1996. Effective Human Relations: A Guide to peopleat work (3rd Edition). Boston: Prentice-Hall.

[18] RISTOW, A., AMOS, T. and STAUDE, G. 1999. "Transformational leadership and organisational effectiveness in the administration of cricket in South Africa

[19] GOLDEN, C.J. and DORNHEIM, L. 1998. "Development and validation of a measure of emotional intelligence", Personality and Individual Differences, 25: 167-177.

[20] STEIN, S.J. and BOOK, H.E. 2000. The EQ Edge: EQ and Your Success. Toronto: Stoddart Publishing.

[21] YUKL G. 1998. Leadership in organizations. Englewood Cliffs: Prentice-Hall. 